\title{
ASSOCIATION BETWEEN IRON DEFICIENCY ANEMIA AND HBA1C LEVEL IN DIABETIC PATIENTS WITH CONTROLLED PLASMA GLUCOSE LEVELS.
}

1. MBBS

House Physician General Medicine PIMS Hospital, Islamabad.

2. MBBS, M.Phil

Assistant Professor Chemical

Pathology

Federal Medical and Dental College,

Islamabad

3. MBBS, M.Phil

Assistant Pathology

Khyber Medical College.

4. MBBS, M.Phil

Professor Pathology

PIMS Hospital, Islamabad.

5. MBBS, DMJ

Assistant Professor Forensic Medicine

Federal Medical and Dental College, Islamabad.

Correspondence Address: Dr. Muhammad Ihtesham Khan Assistant Professor Hematology Pathology Department, Khyber Medical College.

ihteshamkhan9@yahoo.com

Article received on: 17/08/2019

Accepted for publication: $16 / 03 / 2020$
Muhammad Danish Qureshi', Saman Waqar², Muhammad Ihtesham Khan ${ }^{3}$, Lubna Naseem Ayesha Haider 5

ABSTRACT... Objectives: To determine association of iron deficiency anemia on hba1c level in diabetic patients. Study Design: Cross Sectional Analytical study. Setting: Department of Pathology PIMS Hospital. Period: From June 2018 to December 2018 (6 months duration). Material \& Methods: A total of 117 diagnosed cases of diabetes mellitus were included in the study. Pregnant women, patients with end-stage renal disease, hypothyroidism, themoglobinopathies, hemolytic anemia, chronic liver disease and malignancy, participants with poorly controlled diabetes, and patient from the northern areas were excluded from the study. Patients were divided according to their fasting plasma glucose (FPG) level. FPG of $126 \mathrm{mg} / \mathrm{dl}$ was used as a cut-off point for dividing the study population into two groups, i.e controlled sugar level (FPG between 100 and $126 \mathrm{mg} / \mathrm{d} \mathrm{L}$ ) and well controlled sugar level (FPG less than $100 \mathrm{mg} / \mathrm{d} \mathrm{L}$ ). Variables such as Hemoglobin, serum ferritin, serum Hba1c level etc. Results: Mean age of study population in the present study was $56.97 \pm 7.29$ years. Out of 117 cases, about $45(38.5 \%)$ cases were female and $72(38.5 \%)$ were male. Male to female ratio was 1: 1.6. Mean FPG level was $103.3 \pm 7.6$ in our study population. The mean hba1c levels in the sample was $6.42 \pm 0.70 \%$. Mean $\mathrm{Hb}$ levels were recorded as $11.5 \pm 2.7$ and $10.9 \pm 3.03 \mathrm{~g} / \mathrm{dl}$, respectively in female and male. From a total of 117 cases, only 66 were identified as having iron deficiency anemia. Only 54 patients had plasma glucose greater than $100 \mathrm{mg} / \mathrm{dl}$. Odds ratio for hba1c $>6.5 \%$ in iron deficient was $3.90(p=0.001)$. Conclusion: Iron deficiency can cause elevated serum hba1c level. Health care providers, including physicians, must consider the iron status before prescribing diabetics treatment on the basis of serum hba1c level.

Key words: $\quad$ Diabetes Mellitus, Fasting Plasma Glucose, Hemoglobin, Serum Iron, Serum Ferritin.

Article Citation: Qureshi MD, Waqar S, Khan MI, Naseem L, Haider A. Association between iron deficiency anemia and HBA1C level in diabetic patients with controlled plasma glucose levels. Professional Med J 2020; 27(9):1849-1854. DOI: 10.29309/TPMJ/2020.27.09.4053

\section{INTROUCTION}

Diabetes mellitus is a major health problem all over the world. ${ }^{1}$ International Diabetes Federation estimated that about 415 million people were diagnosed as having diabetes mellitus in $2015 .^{1}$ It is estimated that the incidence will increase to about 642 million by the end of $2040 .^{1}$ This will lead to massive increase in morbidity and mortality due to complications related to diabetes mellitus. $^{2}$

Hba1c is glycated form of the hemoglobin. It helps in assessing the changes in plasma glucose level in the past two to three months of duration. Now, it is considered as a standard protocol for monitoring glycemic control in diabetic patients. According to the American Diabetic Association, a hba1c value of $\geq 6.5 \%$ is taken as cut-off for diagnosis of diabetes mellitus. It is taken as an alternative to fasting plasma glucose level (FPG) criteria, which is usually taken as $\geq 7 \mathrm{mmol} / \mathrm{L}$. This is so because there is a strong correlation between hba1c and FPG. Hba1c also corresponds with the risk of developing complications in diabetic patients. Therefore, hba1c is considered a reliable tool for the assessment of glycaemic control in diabetic patients. So, using hba1c levels is now the easiest and reliable means of monitoring blood glucose level diabetes mellitus. ${ }^{3}$ The problem is that the hba1c levels are effected by certain other factors like hemoglobinopathies, pregnancy, acute and chronic blood loss, and hemolytic 
anemias. Folate levels, vitamin B12 levels and iron deficiency anemia also effects hba1c levels in the blood. ${ }^{4}$

About one third of the world's population have anemia. About half of them are due to iron deficiency. Serum ferritin is a diagnostic test for iron deficiency anemia because it gives an estimation of iron store in human body. ${ }^{6}$ The estimated prevalence of anemia in diabetic patients is about $10 \%$ to $30 \%$. One third of them have iron deficiency anemia. ${ }^{7}$ Iron deficiency anemia has been found to cause an increase in the hba1c level. ${ }^{5}$ This is so because anemia tends to decrease the turnover of the red blood cells, which in turn increases the life span of the red blood cells. ${ }^{5,6,7}$

Hba1clevel is of diagnostic significance in diabetes mellitus. As its level is effected by iron deficiency anemia, so it becomes problem for clinicians to diagnose diabetes who have underlying iron deficiency. The elevated levels of hba1c in iron deficiency anemia independent to glycemia has been shown in several. ${ }^{7,8,9}$ Coban et al showed in his study that an elevated hba1c level in iron deficiency can decrease after iron supplementary therapy. Unfortunately, inadequate work has been done to show the effects of iron deficiency on hba1c level in diabetic individuals. Hence we conducted a study to define more valuable numbers on the effect of iron deficiency on hba1c in diabetics.

\section{MATERIAL \& METHODS}

This was a Cross sectional analytical study conducted in Pathology department of PIMS hospital, Islamabad. This hospital is a Public sector tertiary care setup in the Capital city. Ethical approval was obtained from the ethical committee before starting the study. Most of the patients who come here for treatment are residents of the twin cities of Islamabad and Rawalpindi. It also receives a huge bulk of patients from the Northern areas of Pakistan. A total of 811 patients were diagnosed as having diabetis mellitus during the study period. Patients who were pregnant, had end-stage renal disease, hypothyroidism, hemoglobinopathies, hemolytic anemia, chronic liver disease and malignancy were excluded from the study. Patients who had poorly controlled diabetes were also excluded. People who came from northern areas were excluded from the study in order to avoid any environmental influence in our study. So, the remaining 117 diagnosed cases of diabetes mellitus, with age of 15 years to 80 years were included in the study. Fasting plasma glucose level of less than $126 \mathrm{mg} / \mathrm{dl}$ was considered as a cutoff for categorizing patient as having controlled diabetes (FPG between 100 and $126 \mathrm{mg} / \mathrm{d} \mathrm{L}$ ) and well controlled diabetes (FPG less than $100 \mathrm{mg} / \mathrm{d}$ $\mathrm{L})$. Data regarding hba1c level, Hemoglobin $(\mathrm{Hb})$, mean cell volume (MCV), mean cell hemoglobin concentration (MCHC), mean cell hemoglobin $(\mathrm{MCH})$, Serum Ferritin, Serum Iron, and fasting Plasma levels were recorded and results were drawn accordingly. Hemoglobin, MCV and $\mathrm{MCH}$ was measured using electrical impedance technology on semi-automated hematology analyzer Sysmex XP100. Ferritin was measured using electrochemiluminescence technology on fully automated immune assay analyzer Cobas 6000 by sandwich method. Hba1c and fasting plasma glucose (FPG) was measured spectrophotometrically on fully automated analyzer Cobas 6000. Hba1c was measured by turbidimetric inhibition immunoassay (TINIA) for hemolyzed whole blood method and fasting plasma glucose was measured by hexo kinase method. IBM SPSS 22.0 was used for data analysis. Mean and standard deviation were used for quantitative data like age, while frequency and percentages were used for qualitative data like gender. Student independence t-test was used to compare numerical data and categorical data was analyzed by apply chi-square plus odds ratio analysis. Odds ratio are presented with 95\% confidence interval Pearson Coefficient of correlation was calculated to find out any correlation between the variables. Statistically significance is assumed if $p<0.05$.

\section{RESULTS}

Mean age of study population in the present study was $56.97 \pm 7.29$ years. Out of 117 cases, about $45(38.5 \%)$ cases were female and 72 (38.5\%) were male. Male to female ratio was 1 : 
1.6. The mean hba1c levels in the study sample was $6.42 \pm 0.70 \%$. The base line characteristics are shown in Table-I.

Mean Fasting Plasma Glucose of the study sample was $103.3 \pm 7.6 \mathrm{gm} / \mathrm{d} \mathrm{L}$. Mean hemoglobin level in males and females was $11.5 \pm 2.7$ and $10.9 \pm 3.03$ $\mathrm{g} / \mathrm{dl}$, respectively. Figure-1 gives a view about gender distribution of Hemoglobin levels in anemic and non-anemic patients. Mean ferritin level in male and female were $26.6 \pm 23.3$ and $38.25 \pm 36.97 \mathrm{ng} / \mathrm{ml}$, respectively. The mean $\mathrm{MCH}$ levels were $25.1 \pm 6.4 \mathrm{pg} / \mathrm{cell}$ and mean $\mathrm{MCV}$ levels were $69.6 \pm 21.3 \mathrm{FL}$ in the study sample.

About 66 (56.4\%) of cases had iron deficiency anemia (IDA). Average age of anemic and nonanemic cases was $58.3 \pm 8.1$ and $55.3 \pm 5.8$ years, respectively (see Table-II). Moreover, average age of anemic male was $60.1 \pm 8.2$ years which is statistically significant $(p=0.003)$ from $54.8 \pm 0.6$ years in non-anemic. Mean hba1c in subjects of age $>50$ and $\leq 50$ was $6.38 \pm 9.92$ and $6.43 \pm 0.62$, $(p=0.751)$ respectively (see Table-III). Odds ratio for female having hba1c $>6.5 \%$ is $2.29(p=0.032)$ as compared to males (see Table-IV).

The odds ratio of controlled FPG for elevating hba1c $>6.5 \%$ is 5.03 as compared to wellcontrolled FPG. There were 54 (46.2\%) patients who had fasting plasma glucose of greater than $120 \mathrm{mg} / \mathrm{dl}$. Mean hba1c in those anemic and non-anemic individuals was $6.82 \pm 0.79 \%$ and $6.60 \pm 0.44 \%$, respectively (see table $5-a$ ). Pearson Coefficient was statistically significant for FPG and hba1c $(r=0.368, p=0.01)$ in anemic and non-anemic $(r=0.851, p=0.01)$. Interestingly odds ratio for hba1c $>6.5 \%$ in iron deficient was $3.90(p=0.001)$.

\begin{tabular}{|c|c|}
\hline Characteristic of Study Population & N (\%) \\
\hline $\begin{array}{l}\text { Males } \\
\text { Females }\end{array}$ & $\begin{array}{l}72(61.5 \%) \\
45(38.5 \%)\end{array}$ \\
\hline $\begin{array}{l}\text { Smokers } \\
\text { Non smokers }\end{array}$ & $\begin{array}{l}48(41 \%) \\
69(59 \%)\end{array}$ \\
\hline Patients with Iron Deficiency Anemia & $66(56.4 \%)$ \\
\hline Characteristics of the study population & Mean \pm SD \\
\hline Age (years) & $57.0 \pm 7.3$ \\
\hline Fasting Plasma Glucose (gm/dl) & $103.3 \pm 7.6$ \\
\hline Hba1c (\%) & $6.4 \pm 0.7 \%$ \\
\hline $\mathrm{Hb}$ in female (gm/d L) & $10.9 \pm 3.0$ \\
\hline Mean $\mathrm{Hb}$ in male (gm/d L) & $11.5 \pm 2.7$ \\
\hline MCV (femto Litre) & $69.6 \pm 21.3$ \\
\hline $\mathrm{MCH}(\mathrm{gm} / \mathrm{d} \mathrm{L})$ & $25.1 \pm 6.4$ \\
\hline Ferritin in female (ng/m L) & $26.6 \pm 23.3$ \\
\hline Ferritin in male (ng/m L) & $38.3 \pm 37.0$ \\
\hline
\end{tabular}

\begin{tabular}{|c|c|c|c|c|c|c|}
\hline & \multicolumn{2}{|c|}{ Female $(n=45)$} & \multicolumn{2}{|c|}{ Male $(n=72)$} & \multicolumn{2}{|c|}{ Total } \\
\hline Hba1c & $7.05 \pm 0.33^{*}$ & $5.857 \pm 0.561$ & $6.457 \pm 0.694$ & $5.480 \pm 5.36$ & $6.673 \pm 0.652^{*}$ & $6.08 \pm 0.61$ \\
\hline
\end{tabular}




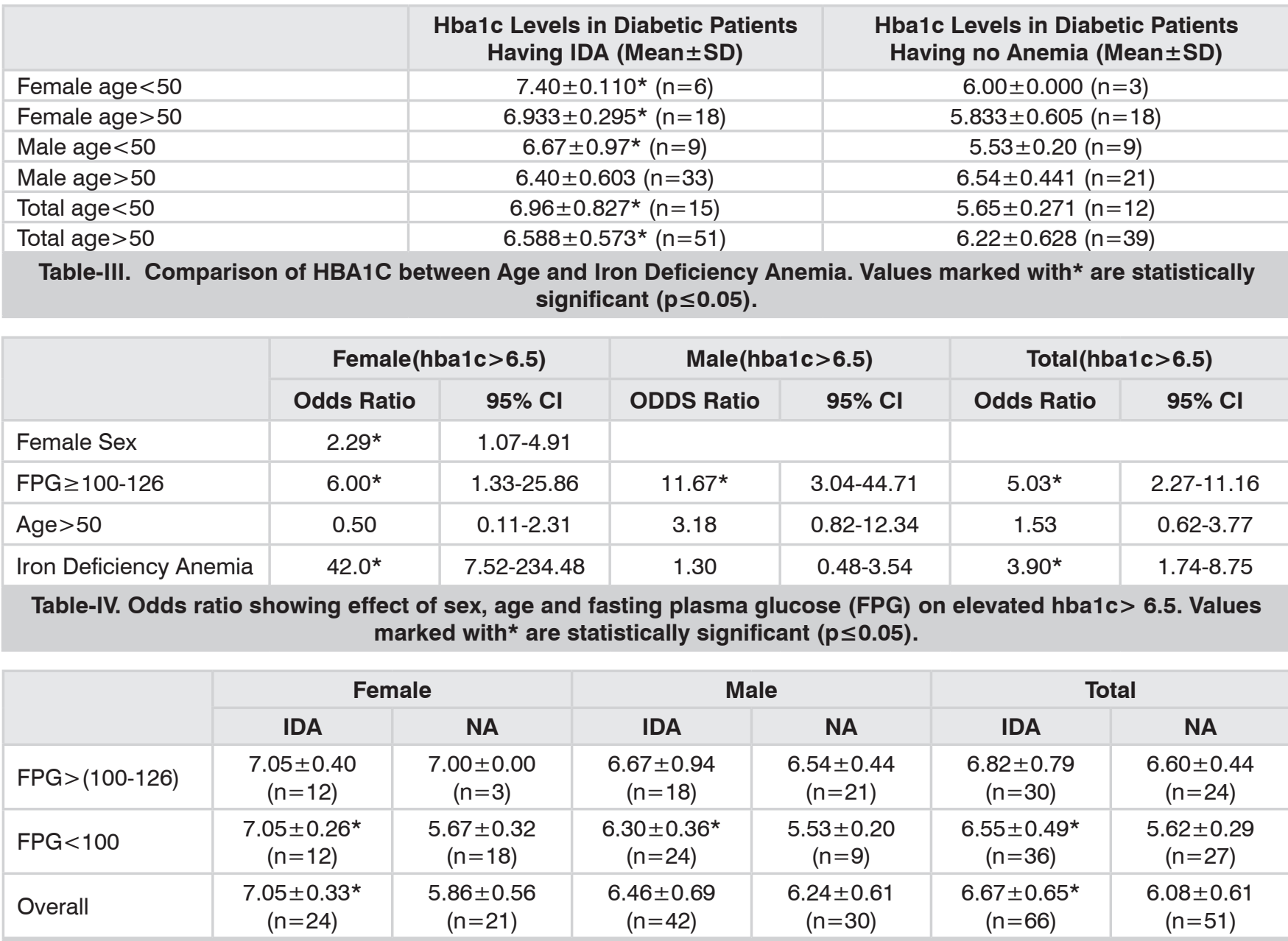

Table-V-a. Mean HBA1C in controlled and Well-controlled diabetics. Values marked with* are statistically significant (statistical significance is achieved by using t-test between anemia and non-anemia).

\begin{tabular}{|c|c|c|c|c|c|c|}
\hline & \multicolumn{2}{|c|}{ Female } & \multicolumn{2}{|c|}{ Male } & \multicolumn{2}{|c|}{ Total } \\
\hline & $F P G>(100-126)$ & $F P G<100$ & $F P G>(100-126)$ & $F P G<100$ & $F P G>(100-126)$ & $F P G<100$ \\
\hline IDA & $\begin{array}{c}7.05 \pm 0.40 \\
(n=12)\end{array}$ & $\begin{array}{c}7.05 \pm 0.26 \\
(n=12)\end{array}$ & $\begin{array}{c}6.67 \pm 0.94 \\
(n=18)\end{array}$ & $\begin{array}{c}6.30 \pm 0.36 \\
(n=24)\end{array}$ & $\begin{array}{c}6.82 \pm 0.79 \\
(n=30)\end{array}$ & $\begin{array}{c}6.55 \pm 0.49 \\
(n=36)\end{array}$ \\
\hline NA & $\begin{array}{c}7.00 \pm 0.00 * \\
(n=3)\end{array}$ & $\begin{array}{c}5.67 \pm 0.32 \\
(n=18)\end{array}$ & $\begin{array}{c}6.54 \pm 0.44^{*} \\
(n=21)\end{array}$ & $\begin{array}{c}5.53 \pm 0.20 \\
(n=9)\end{array}$ & $\begin{array}{c}6.60 \pm 0.44^{\star} \\
(n=24)\end{array}$ & $\begin{array}{c}5.62 \pm 0.29 \\
(n=27)\end{array}$ \\
\hline Overall & $\begin{array}{c}7.04 \pm 0.36 * \\
(n=15)\end{array}$ & $\begin{array}{c}6.22 \pm 0.75 \\
(n=30)\end{array}$ & $\begin{array}{c}6.60 \pm 0.71 \text { * } \\
(n=39)\end{array}$ & $\begin{array}{c}6.09 \pm 0.48 \\
(n=33)\end{array}$ & $\begin{array}{c}6.72 \pm 0.66^{\star} \\
(n=54)\end{array}$ & $\begin{array}{c}6.15 \pm 0.62 \\
\quad(n=63)\end{array}$ \\
\hline
\end{tabular}

Table-V-b. Mean hba1c in Controlled and Well-controlled diabetics. Values marked with* are statistically significant (statistical significance is achieved by using t-test between controlled and well-controlled). IDA: iron deficiency anemia, NA:Non anemia

\begin{tabular}{|c|c|c|}
\hline & IDA & NA \\
\hline $\mathrm{FPG}>(100-126)$ & $0.405^{\star}$ & $0.613^{\star}$ \\
\hline$F P G<(100)$ & $0.623^{*}$ & 0.161 \\
\hline
\end{tabular}




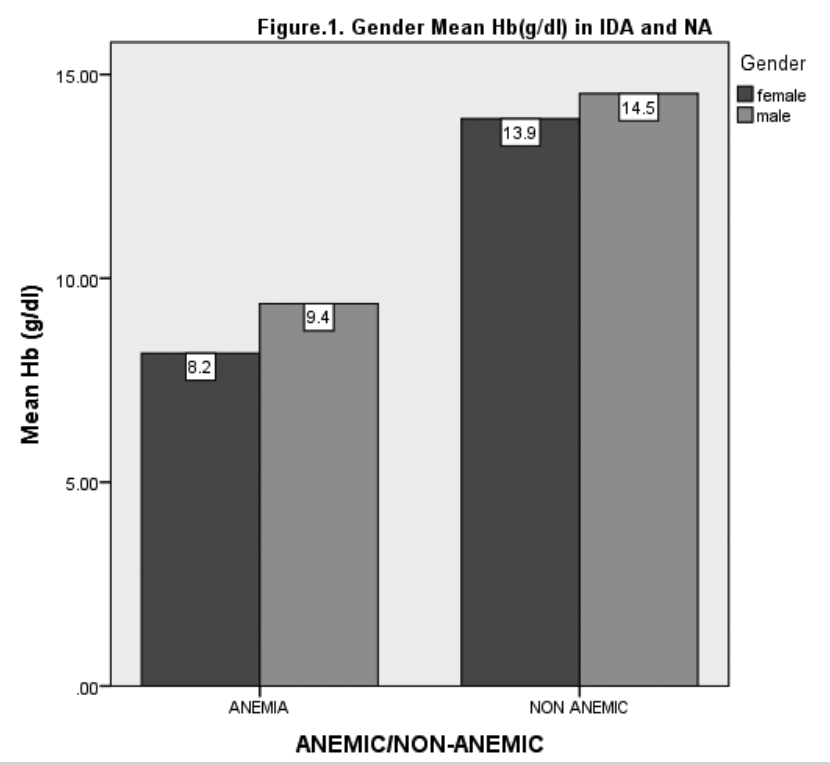

Figure-1. Gender Mean $\mathrm{Hb}(\mathrm{g} / \mathrm{dl})$ in IDA and NA

\section{DISCUSSION}

Hba1c is one of the most important protein of our body. There are many factors that effects the synthesis of hba1c. It can be both physiological and pathological. ${ }^{12}$ Iron deficiency states can influence serum hba1c levels in the body. Although there have been much work done to find out the association of iron deficiency anemia and hba1c level in diabetic patients. However, very limited work is done to find this association in diabetics who have a controlled sugar level. Diabetic patients are treated with anti diabetic drugs with a target to achieve their hba1c to less than $6 \%$. This level corresponds with $126 \mathrm{mg} / \mathrm{dl}$ of fasting plasma sugar level. ${ }^{10}$ Sometimes diabetic patients show non-compliance with the treatment and physicians have to change the regime. ${ }^{12}$

In the present study, it was found that iron deficient patients had a significantly high levels of hba1c than non-anemic patients (see Table$\mathrm{V}-\mathrm{a}$ and Figure-2). And interestingly, there was no significant difference of hba1c levels of controlled and well-controlled diabetic iron deficient groups. In contrast, non-anemic patients showed significantly increased hba1c in controlled as compared to well control (see Table-V-b). The present study also showed an increased levels of hba1c in anemic as compared to non-anemic group in both sexes. However, only the female

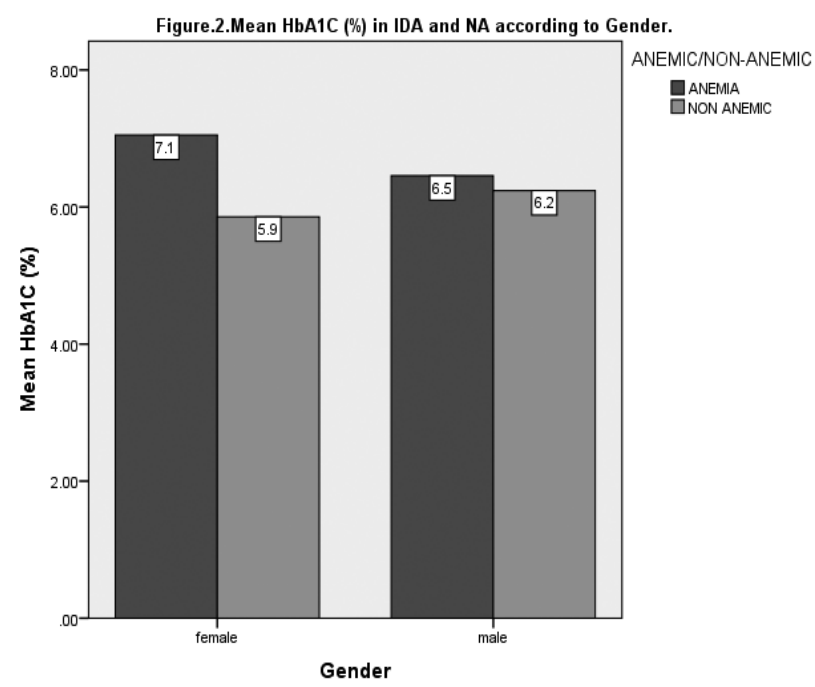

Figure-2. Mean HbA1C (\%) in IDA and NA according to gender.

patients demonstrated statistical significant difference between the two groups (see Table$\mathrm{V}$-a). Therefore, female patients were more prone for having elevated hba1c. As already mentioned that female patients had a significant odds ratio for having hba1c $>6.5 \%$. On the other hand, males had no significant difference in hba1c level between anemic and non-anemic group $(6.46=0.69 \%$ and $6.24=0.61 \%$, respectively).

In the present study, it was shown that that the patients who maintained controlled diabetes had a significantly high hba1c level as compared to well-control diabetes (see Table-V-b). Interestingly, further stratification into anemic and non-anemic as illustrated in Table-V-a has established a connection that only people with well-controlled diabetes and having anemia maintained significantly high level of hba1c (see Table-V-a). In other words, iron deficiency tended to elevate hba1c more in people who had a well-controlled diabetes. The fact is also demonstrated by the fact that well-controlled diabetics who were also anemic showed a significant Pearson coefficient of correlation $(r=0.623)$ between FPG and hba1c, depicting a strong +ve correlation (see Table$\mathrm{VI})$. Whereas the other group has shown an insignificant Pearson coefficient $(r=0.161)$.

A study done by Davidson have shown small 
correlation between age and HBA1C. ${ }^{11}$ Likewise, the present study have also provided the fact that there is insignificant difference of hba1c level between different age group. Ferritin has been implicated as an indicator of iron storage. ${ }^{13,14}$ In the present study, it was found that there was no correlation between hba1c and Ferritin level $(r=0.060, p=0.524)$.

\section{CONCLUSION}

Iron deficiency is associated with a high level of hba1c even with a well-controlled diabetes. Physicians must detect Hemoglobin level and iron levels before starting anti-diabetic treatment. Moreover, females were at a greater risk of elevating hba1c levels in diabetics.

Copyright@ 16 Mar, 2020.

\section{REFERENCES}

1. Herman $\mathrm{WH}$. The global burden of diabetes: An overview. In diabetes mellitus in developing countries and underserved communities 2017 (pp. 1-5). Springer, Cham.

2. Reusch JE, Manson JE. Management of type 2 diabetes in 2017: Getting to goal. Jama. 2017; 317(10):1015-6.

3. Sherwani SI, Khan HA, Ekhzaimy A, Masood A, Sakharkar MK. Significance of hba1c test in diagnosis and prognosis of diabetic patients. Biomarker insights. 2016; 11:BMI-S38440.

4. Sinha N, Mishra TK, Singh T, Gupta N. Effect of iron deficiency anemia on hemoglobin A1c levels. Annals of laboratory medicine. 2012; 32(1):17-22.

5. English E, Idris I, Smith G, Dhatariya K, Kilpatrick ES, John WG. The effect of anaemia and abnormalities of erythrocyte indices on hba1c analysis: A systematic review. Diabetologia. 2015; 58(7):1409-21.
6. Babaei M, Shafiei S, Bijani A, Heidari B, Hosseyni SR, Vakili Sadeghi M. Ability of serum ferritin to diagnose iron deficiency anemia in an elderly cohort. Revista brasileira de hematologia e hemoterapia. 2017; $39(3): 223-8$.

7. Hong JW, Ku CR, Noh JH, Ko KS, Rhee BD, Kim DJ. Association between the presence of iron deficiency anemia and hemoglobin A1c in Korean adults: The 2011-2012 Korea National Health and Nutrition Examination Survey. Medicine. 2015; 94(20).

8. Tarim ÖM, Küçükerdogan AY, Günay ÜN, Eralp ÖZ, Ercan i. Effects of iron deficiency anemia on hemoglobin A1c in type 1 diabetes mellitus. Pediatrics international. 1999; 41(4):357-62.

9. Coban E, Ozdogan M, Timuragaoglu A. Effect of iron deficiency anemia on the levels of hemoglobin A1c in nondiabetic patients. Acta haematologica. 2004; 112(3):126-8

10. American Diabetes Association. Executive summary: Standards of medical care in diabetes--2011. Diabetes Care. 2011; 34:S4.

11. Davidson $M B$, Schriger $\mathrm{DL}$. Effect of age and race/ ethnicity on hba1c levels in people without known diabetes mellitus: Implications for the diagnosis of diabetes. Diabetes research and clinical practice. 2010. $87(3): 415-21$

12. Urrechaga $E$. The influence of Iron status in Hba1c analysis. SM J Diabetes Metab. 2016; 1(1):1004.

13. Daru J, Colman K, Stanworth SJ, De La Salle B, Wood EM, Pasricha SR. Serum ferritin as an indicator of iron status: what do we need to know? The American journal of clinical nutrition. 2017; 106(suppl_6):1634S$9 S$.

14. Raj S, Rajan GV. Correlation between elevated serum ferritin and hba1c in type 2 diabetes mellitus. International Journal of Research in Medical Sciences. $2017 ; 1(1): 12-5$.

\begin{tabular}{|c|l|l|l|}
\hline \multicolumn{3}{|c}{ AUTHORSHIP AND CONTRIBUTION DECLARATION } \\
\hline Sr. \# & \multicolumn{1}{|c|}{ Author(s) Full Name } & \multicolumn{1}{|c|}{ Contribution to the paper } & Author(s) Signature \\
\hline 1 & M. Danish Qureshi & Principle author. \\
2 & Saman Waqar & Discussion. \\
3 & M. Ihtesham Khan & $\begin{array}{l}\text { Correspondance, review of } \\
\text { article. } \\
\text { Proof reading. }\end{array}$ \\
\hline 5 & Lubna Naseem & $\begin{array}{l}\text { Ayesha Haider } \\
\text { Literature review. }\end{array}$ \\
\hline
\end{tabular}

